\title{
-Cyclocitral, a Grazer defence signal unique to the cyanobacterium microcystis
}

\author{
Jüttner, Friedrich ; Watson, Susan B ; von Elert, Eric ; Köster, Oliver
}

\begin{abstract}
Cyclocitral is often present in eutrophic waters and is a well known source of airborne and drinking water malodor, but its production and functional ecology are unresolved. This volatile organic compound (VOC) is derived from the catalytic breakdown of -carotene, and evidence indicates that it is produced by the activation of a specific carotene oxygenase by all species of the bloom-forming cyanobacterium Microcystis. Previous work has shown that -cyclocitral affects grazer behavior, but the nature of this interaction and its influence on predator-prey dynamics was unresolved. The present study combined analytical and behavioral studies to evaluate this interaction by using Microcystis NRC- 1 and Daphnia magna. Results showed that -cyclocitral was undetectable in live Microcystis cells, or present only at extremely low concentrations (2.6 amol / cell). In contrast, cell rupture activated a rapid carotene oxygenase reaction, which produced high amounts $(77 \pm 5.5 \mathrm{amol}$-cyclocitral/cell), corresponding to a calculated maximum intracellular concentration of $2.2 \mathrm{mM}$. The behavioral response of Daphnia magna to -cyclocitral was evaluated in a bbe@ Daphnia toximeter, where -cyclocitral treatments induced a marked increase in swimming velocity. Acclimation took place within a few minutes, when Daphnia returned to normal swimming velocity while still exposed to -cyclocitral. The minimum VOC concentration (odor threshold) that elicited a significant grazer response was $750 \mathrm{nM}$-cyclocitral, some 2,900 times lower than the per capita yield of a growing Microcystis cell after activation. Under natural conditions, initial grazerrelated or other mode of cell rupture would lead to the development of a robust -cyclocitral microzone around Microcystis colonies, thus acting as both a powerful repellent and signal of poor quality food to grazers
\end{abstract}

DOI: https://doi.org/10.1007/s10886-010-9877-0

Posted at the Zurich Open Repository and Archive, University of Zurich

ZORA URL: https://doi.org/10.5167/uzh-155893

Journal Article

Published Version

Originally published at:

Jüttner, Friedrich; Watson, Susan B; von Elert, Eric; Köster, Oliver (2010). -Cyclocitral, a Grazer defence signal unique to the cyanobacterium microcystis. Journal of Chemical Ecology, 36(12):13871397.

DOI: https://doi.org/10.1007/s10886-010-9877-0 


\title{
$\beta$-Cyclocitral, a Grazer Defence Signal Unique to the Cyanobacterium Microcystis
}

\author{
Friedrich Jüttner • Susan B. Watson • Eric von Elert • \\ Oliver Köster
}

Received: 7 April 2010 /Revised: 5 October 2010 / Accepted: 26 October 2010 /Published online: 12 November 2010

(C) Springer Science+Business Media, LLC 2010

\begin{abstract}
Cyclocitral is often present in eutrophic waters and is a well known source of airborne and drinking water malodor, but its production and functional ecology are unresolved. This volatile organic compound (VOC) is derived from the catalytic breakdown of $\beta$-carotene, and evidence indicates that it is produced by the activation of a specific carotene oxygenase by all species of the bloomforming cyanobacterium Microcystis. Previous work has shown that $\beta$-cyclocitral affects grazer behavior, but the nature of this interaction and its influence on predator-prey dynamics was unresolved. The present study combined analytical and behavioral studies to evaluate this interaction by using Microcystis NRC-1 and Daphnia magna. Results showed that $\beta$-cyclocitral was undetectable in live Microcystis cells, or present only at extremely low concentrations
\end{abstract}

\section{F. Jüttner $(\bowtie)$}

University of Zürich,

Limnological Station,

CH-8802, Kilchberg, Switzerland

e-mail: juttner@limnol.uzh.ch

\section{S. B. Watson}

Aquatic Ecosystem Management Research Canada

Centre for Inland Waters, Environment Canada,

867, Lakeshore Rd,

Burlington, ON, Canada

e-mail: sue.watson@ec.gc.ca

E. von Elert

University of Cologne,

Cologne Biocentre, Zülpicher Strasse 47b,

50674, Köln, Germany

e-mail: evelert@uni-koeln.de

\section{O. Köster}

Zürich Water Supply (WVZ),

Hardhof 9, P.O. Box 1179, CH-8021, Zürich, Switzerland

e-mail: oliver.koester@zuerich.ch
(2.6 amol /cell). In contrast, cell rupture activated a rapid carotene oxygenase reaction, which produced high amounts (77 $\pm 5.5 \mathrm{amol} \beta$-cyclocitral/cell), corresponding to a calculated maximum intracellular concentration of $2.2 \mathrm{mM}$. The behavioral response of Daphnia magna to $\beta$-cyclocitral was evaluated in a bbe (C) Daphnia toximeter, where $\beta$ cyclocitral treatments induced a marked increase in swimming velocity. Acclimation took place within a few minutes, when Daphnia returned to normal swimming velocity while still exposed to $\beta$-cyclocitral. The minimum VOC concentration (odor threshold) that elicited a significant grazer response was $750 \mathrm{nM} \beta$-cyclocitral, some 2,900 times lower than the per capita yield of a growing Microcystis cell after activation. Under natural conditions, initial grazer-related or other mode of cell rupture would lead to the development of a robust $\beta$-cyclocitral microzone around Microcystis colonies, thus acting as both a powerful repellent and signal of poor quality food to grazers.

Key Words $\beta$-Cyclocitral - Microcystis - Daphnia - Odor threshold concentration · Grazer repellent . Chemical signal

\section{Introduction}

There is a global perception that harmful cyanobacterial blooms have increased significantly in occurrence and severity over the past few decades as a result of widespread eutrophication of inland waters. Reports of algal blooms date back to ancient times, but growing concern with their apparent recent increase has elicited numerous studies aimed at identifying the key mechanisms that promote these outbreaks (e.g., Watson et al. 2008). Most of this work has focussed on 'bottom-up' factors, with particular emphasis on nutrients and other modifying factors such as 
temperature, $\mathrm{pH}$, alkalinity, mixing regime, and light, many of which show significant relationships to cyanobacteria biomass and dominance (Watson et al. 1997; Dokulil and Teubner 2000).

Among the bloom-forming cyanobacteria, particular attention has been paid to Microcystis, a colonial, buoyancy controlling K-strategist (Benndorf and Henning 1989). Species of Microcystis are widely distributed in eutrophic (Reynolds 2006) and hypereutrophic lakes (Kotak et al. 1995) and rivers (Krogmann et al. 1986), where they can develop dense, potentially toxic blooms. Extensive research has focussed on the ecophysiology of these cyanobacteria, and several key mechanisms have been proposed that may provide these taxa with a competitive edge over other species. These studies have focused primarily on bottom-up factors related to light, mixing and nutrient uptake; others have recognized the potential importance of size-selective grazing (Hyenstrand et al. 1998). However, there is a growing body of evidence to suggest that more subtle grazer interactions controlled by allelochemicals play important but poorly understood roles (DeMott and Tessier 2002; Hansson et al. 2007).

Under natural conditions, the cells of Microcystis are embedded in a matrix of mucilage and form colonies with sizes up to $8 \mathrm{~mm}$ in diameter (Joosten 2006). Large colonies often exceed the maximum ingestible size range of even large freshwater crustaceans that is in the range of $75 \mu \mathrm{m}$ for an adult Daphnia magna (Burns 1968). This provides little protection, however, for smaller Microcystis colonies and single cells, which remain within the food spectrum even of small sized crustaceans (Fulton and Paerl 1987a; Jarvis et al. 1987; Rohrlack et al. 1999a; Ghadouani et al. 2004). In addition to providing the colonial matrix, evidence suggests that a second protective function may be involved by the externally produced mucilage. Daphnia showed lower ingestion and increased its labral rejection rate of small colonies and single cells covered with robust mucilage compared to mucilage poor cells (Rohrlack et al. 1999a; Ghadouani et al. 2004). Indirect chemical interactions that promote grazer selectivity also may influence some top-down processes. For example, sterols are essential membrane constituents of animal grazers, and can only partially be synthesized by crustaceans (von Elert et al. 2003). A form of non-specific biochemical defense may be accomplished by the extremely low production of these sterols by all cyanobacteria including Microcystis, which may lead to reduced grazing losses as herbivores may prefer ingestion of food items of higher quality (Koski et al. 2006)

More direct chemical defense may be provided by the production of toxic microcystins, which are potent inhibitors of eukaryote protein phosphatase 1 and 2A. Comparisons of microcystin-producing and non-producing
Microcystis strains as sole food for crustaceans have reported both toxic and non-toxic effects (Wilson et al. 2006). However, these experiments have failed to address some important confounding factors: Notably, i) differences in Microcystis chemotypes among studies or in field populations; ii) among- and within-strain variance in production of multiple microcystin congeners of different toxicity; iii) the co-production of other bioactive oligopeptides by Microcystis (Welker et al. 2006; Jüttner and Lüthi 2008); iv) differences in the genetic capacity for toxin production and its activation, even within the same bloom (Rinta-Kanto et al 2009); and v) the development of grazer resistance (DeMott et al. 1991). More definitive evidence has been obtained by using a mutant strain of Microcystis PCC 7806 that lacks the microcystin synthetase gene $m c y B$, but that does not affect synthesis of other oligopeptides (Rohrlack et al. 1999b). Only the wild type exhibited toxicity to Daphnia galeata and clearly showed the efficiency of microcystins. Other Microcystis secondary metabolites also have a direct inhibitive or toxic effect. The oligopeptides aeruginosins and cyanopeptolins are effective serine protease inhibitors (Ishida et al. 1999; Bister et al. 2004), microviridin J disrupts moulting (Rohrlack et al. 2003), and aerucyclamides are bioactive (Portmann et al. 2008) but the molecular targets are not yet known. Serine protease inhibitors severely affect the hydrolytic cleavage of serine proteases isolated from Daphnia gut, likely having a similar effect under natural conditions (von Elert et al. 2004).

As known in many examples from higher plants, unsuitable food organisms produce warning signals that alert grazers. Volatile organic compounds (VOCs) are widely used by different taxa to locate and evaluate other organisms in the environment by a form of 'remote sensing'. These allelochemicals include pheromones, attractants, and repellents (Watson 2003; Fink 2007). In terrestrial ecosystems, volatiles are airborne, and both primitive and highly advanced organisms have developed extremely sensitive odor receptors that detect trace concentrations of them. In aquatic ecosystems, the matrix for VOC distribution is water or biofilm mucilage (Jüttner 1999). Many of the allelochemicals identified to date are lipophilic, but they can induce behavioral responses in target organisms at trace levels. Hence, their signalling function is not impaired by their low water solubility - as seen, for example, with marine phaeophyte spermatozoids, which are attracted to mature eggs by pheromones (alkenes) at picomolar concentrations (Boland et al. 1995).

While VOCs may reduce ingestion and may have toxic properties, there has been little convincing evidence to suggest that they function in a more subtle manner, by influencing grazer behavior towards Microcystis. However, intriguing preliminary evidence has implicated a VOC derived from photosynthetic pigments that may, in fact, 
function in this indirect manner. This was based on early studies, which demonstrated clearly that for all Microcystis strains tested, cell disruption activates the rapid cleavage of $\beta$-carotene by an unique carotene dioxygenase, forming two major derivatives, $\beta$-cyclocitral, a volatile that is released into the water, and crocetindialdehyde, a nonvolatile product which remains associated with the cell debris (Jüttner 1984; Jüttner and Höflacher 1985). $\beta$-Cyclocitral is a well known odor compound that affects drinking water supplies, and gives Microcystis blooms a characteristic haytobacco odor, but its role in aquatic chemical defense against grazers has only recently been examined (Watson et al. 2007). As a lipophilic VOC, $\beta$-cyclocitral is well suited as a chemical signal. In recent experiments, we observed a strong and immediate increase in swimming velocity of Daphnia magna at low concentrations of this compound (Watson et al. 2007). In the present study, we elucidated this reaction in more detail, by testing the hypothesis that $\beta$-cyclocitral serves as a signal for food avoidance and induces a phobic response of $D$. magna. We also quantified this process on a molecular level, thus providing the basis for calculating this microscale biochemical interaction that occurs during Daphnia-Microcystis interactions.

\section{Methods and Materials}

Microcystis Microcystis NRC-1 (Microcystis sp. Zehnder 1954 / NRC-1, identical with SAG B14.85) was obtained originally from the Institute of Botany, Culture Collection of Autotrophic Organisms, Trěboň, Czechoslovakia in 1988, and since, it has been held at the Univerity of Zürich, Department of Limnology where it has been maintained in batch culture $(120 \mathrm{ml})$ in $300-\mathrm{ml}$ Erlenmeyer flasks at $20^{\circ} \mathrm{C}$ under continuous light of $7 \mathrm{\mu molm}^{-2} \mathrm{sec}^{-1}$ from fluorescent tubes in cyanobacterial mineral medium (Jüttner and Lüthi 2008). Experiments were carried out by using 16-d-old culture material with average cell diameter of $4.1 \mu \mathrm{m}$ and cell volume $35 \mu^{3}$ (as determined by light microscopy).

Daphnia Magna Standardized, 1- to 2-d-old D. magna were raised from 3-wk-old mothers from a single genetic strain (Watson et al. 2007). Each behavior experiment was performed with individuals of equivalent size, taken from a single age-class cohort of Daphnia. Eight animals were held in each of two parallel flow-through glass cells $(36 \mathrm{ml})$ of a bbe(C) Daphnia Toximeter (bbe Moldaenke, Kiel-Kronshagen, Germany), continually supplied with an inflow of untreated bank filtrate from the Limmat River, Zürich, at a constant flow rate and temperature $\left(9 \mathrm{mlmin}^{-1}\right.$ at $\left.20^{\circ} \mathrm{C} \pm 0.2^{\circ} \mathrm{C}\right)$. The Daphnia were fed on a controlled supply of algal food (Scenedesmus acuminatus) added continually to the cell inflow. Animals were replaced each week, and acclimated for 2-3 days in the flow-through cells before experiments were carried out. The bbeC Daphnia Toximeter is a commercial instrument developed for biomonitoring of toxic compounds in raw water of drinking water industries. Detailed descriptions of the instrument setup, measuring and data system and a flow chart outlining the experimental protocol used here and in previous work are published by Lechelt et al. (2000) and Watson et al. (2007).

Determination of Chlorophyll a One-ml of the Microcystis suspension was applied in triplicate to a glass fiber filter (GF 6, Schleicher \& Schuell, Dassel, Germany) as small spots under low vacuum. The spots were cut out, and each was extracted with $3 \mathrm{ml}$ methanol overnight in a fridge. The full absorption spectrum of the extracts was measured on a spectrophotometer (Cary 3), and the absorption of the maximum at $666 \mathrm{~nm}$ was used to determine the amount of chlorophyll $a$ (Ogawa and Vernon 1971).

Determination of Cell Counts by Flow Cytometry Twenty$\mathrm{ml}$ suspensions of Microcystis first were preserved with $100 \mu \mathrm{l}$ Lugol's solution (0.5\%) and then with $2 \mathrm{ml} \mathrm{20 \%}$ formaldehyde. After decolorization with $100 \mu \mathrm{l} 0.1 \mathrm{~mol} / 1$ sodium thiosulphate, $10 \mu$ Sybr Green I solution (No 7563, Invitrogen, Basel, Switzerland) that had been diluted 1:100 with dimethylsulfoxide were added to $1 \mathrm{ml}$ diluted cell suspension. After staining for $15 \mathrm{~min}$, the cell concentration was determined with a CyFlow space (Partec $\mathrm{GmbH}$, Münster, Germany). The excitation at $488 \mathrm{~nm}$ gave strong signals in the green emission range.

$\beta$-Cyclocitral in Live Microcystis Cells The concentration of $\beta$-cyclocitral in live Microcystis cells was determined by minimizing the activation of carotene oxygenase by addition of trifluoroacetic acid. A volume of $250 \mu \mathrm{l}$ from a 16-d-old Microcystis suspension was suspended in fresh growth medium $\left(3.5 \times 10^{7}\right.$ cells $\left./ \mathrm{ml}\right)$ and transferred into a $250 \mathrm{ml}$ round bottom stripping vessel containing $250 \mu \mathrm{l}$ of $0.05 \%$ $(\mathrm{v} / \mathrm{v})$ trifluoroacetic acid to immediately kill the cells. Ten $\mathrm{ml}$ of water then were added, and the suspension was neutralized with $\mathrm{NaHCO}_{3}$. The volume was increased to $50 \mathrm{ml}$ with water, $2 \mu \mathrm{l}$ of a $R$-pulegone solution (11.2 ng / $\mu$ l methanol) were added as the internal standard, and $\beta$-cyclocitral was analyzed by using the protocol described below.

Quantitative Analysis of $\beta$-Cyclocitral and Hydrocarbons $\beta$ Cyclocitral and other volatile hydrocarbons were extracted from the samples onto Tenax cartridges by using a closedloop stripping technique, and analyzed quantitatively on a GC-MS as described previously (Durrer et al. 1999; Jüttner 2005) but at a capillary column temperature of $50^{\circ} \mathrm{C}$ during thermal desorption. The temperature program of the oven was $4 \mathrm{~min}$ at $50^{\circ} \mathrm{C}$, then ramped $10^{\circ} \mathrm{C} / \min$ up to $200^{\circ} \mathrm{C}$. 
Under these conditions, $\beta$-cyclocitral and pulegone eluted at 12.24 and $12.55 \mathrm{~min}$, respectively. Single ion chromatograms $\left(\mathrm{m} / z 152\left[\mathrm{M}^{+}\right]\right)$were extracted from the full mass spectra, and the peak areas were integrated. Calibration was performed with $\beta$-cyclocitral (BASF, Ludwigshafen, Germany) and $R$-pulegone (Fluka, Buchs, Switzerland). Straight chain hydrocarbons were obtained as reference compounds from Fluka. 7-Methylheptadecane was synthesized according to Han et al. (1968).

Age-Dependant Production of $\beta$-Cyclocitral by Microcystis Cells Batch cultures of Microcystis were grown for 16 to 207 days and used to investigate age-dependant production of $\beta$-cyclocitral. To remove cell clumps and allow quantitative centrifugation, Microcystis suspensions were passed through a $50 \mu \mathrm{m}$ net and then pressurized in a stainless steel pressure cylinder $(16 \mathrm{~cm}$ high, $10 \mathrm{~cm}$ i.d.) with $2 \mathrm{MPa}$ argon to collapse gas vesicles. GC-MS analysis verified that $\beta$-cyclocitral formation was not initiated by this procedure. The treated suspensions were centrifuged, and the pellets were resuspended in $50 \%$ diluted cyanobacterial medium to a typical cell count of $2 \times 10^{7}$ cells $/ \mathrm{ml}$. A volume of $10 \mathrm{ml}$ then was transferred into a $90-\mathrm{ml}$ test tube and frozen by dipping into liquid nitrogen. After $15 \mathrm{~min}$ at $-196^{\circ} \mathrm{C}$, the pellet was melted 3 min under running tap water and transferred into a glass vial, and closed with a screw cap leaving a small headspace. The subsequent carotene oxygenase reaction was carried out in these tubes for $90 \mathrm{~min}$ at $23^{\circ} \mathrm{C}$. Then $1 \mathrm{ml}$ of the suspension was transferred into an Eppendorf vial with a cap and centrifuged for $1 \mathrm{~min}$. A supernatant volume of $250 \mu \mathrm{l}$ was removed immediately and added below the surface to a rotating $50 \mathrm{ml} 20 \% \mathrm{NaCl}$ solution containing $R$-pulegone as an internal standard. The quantitative determination of $\beta$ cyclocitral was done as outlined above. To determine the potential loss of $\beta$-cyclocitral by the centrifugation process, we analyzed a $100 \mu$ molar solution under the same conditions. The integration values of the peak areas of $\mathrm{m} / \mathrm{z}$ 152 were $0.63 \pm 0.10$ before and $0.57 \pm 0.17($ mean \pm SD) after centrifugation. The concentrations were not statistically different $(t$-test for dependent samples, $t=0.585 ; P=$ 0.590 . The data met the assumptions of normality (ShapiroWilk $W$ test) and homogeneity of variance (Levene's test). We therefore conclude that opening of the samples and subsequent centrifugation in closed Eppendorf vials did not result in a loss of $\beta$-cyclocitral.

Kinetics of $\beta$-Cyclocitral Formation The kinetics of $\beta$ cyclocitral formation were measured by using the above protocol. A volume of $20 \mathrm{ml}$ of a 15-d-old culture of Microcystis was subjected to a freeze-thaw cycle. One mlvolumes were removed after different periods, transferred into an Eppendorf that was closed with a lid, and centrifuged. Further analysis was performed as outlined above. To obtain kinetics for osmotic shock conditions, $5 \mathrm{ml}$ of a Microcystis suspension were mixed with $200 \mathrm{ml}$ $20 \%(\mathrm{w} / \mathrm{v}) \mathrm{NaCl}$ solution, and $50 \mathrm{ml}$-samples were removed after defined incubation times for quantitative analysis by stripping analysis.

Determination of $\beta$-Cyclocitral Odor Threshold for Daphnia The movement of each of the eight individuals of $D$. magna was tracked with a camera in the cell $(36 \mathrm{ml}$ net volume) of a toximeter. Mean values of the swimming velocity were recorded to a database every $50 \mathrm{sec}$ by an intrinsic program. These data were used to determine the odor threshold of $\beta$-cyclocitral for this crustacean, using changes in swimming velocity as an index of compound detection, according to the basic protocol outlined in our previous work (Watson et al. 2007), but with the following modifications. The response to $\beta$-cyclocitral was tested at three different concentrations, $250 \mathrm{nmoll}^{-1}, 750 \mathrm{nmoll}^{-1}$, and $2.5 \mu \mathrm{moll}^{-1}$. To avoid changes in background water quality during an experiment, a total bank filtrate volume of 40-1 of bank filtrate water was first collected at the beginning of each day and stored in 10-1 glass bottles (using a supply flow rate of $72 \mathrm{ml} / \mathrm{min}$ ). The water was supplemented with $5 \mu \mathrm{l}$ ethanol per liter $(=86 \mu \mathrm{mol} / \mathrm{l})$ to control for the solvent used in the $\beta$-cyclocitral treatment. Our earlier work had shown that this ethanol concentration caused no adverse effects or significant change in the swimming velocity of $D$. magna (Watson et al. 2007). To have the same age class of Daphnia, only one experiment was conducted per week.

The mean of four baseline measuring periods, two before and two after switching to $\beta$-cyclocitral spiked water in the inflow, was used to calculate the baseline swimming velocity of ca. $0.5-0.6 \mathrm{cms}^{-1}$. Due to the large void volume of the system, the measurements at that time were actually performed with reference water. The response of swimming velocity of Daphnia was observed 15-18 min after switching to $\beta$-cyclocitral spiked water. This lag period was necessary to attain a detectable $\beta$-cyclocitral concentration in the toximeter cell. The lag period increased slightly with decreasing concentrations of $\beta$-cyclocitral.

Daphnia Behavioral Response to Live Microcystis Cells To show the effect on D. magna swimming velocity elicited by live Microcystis cells, the same experimental setup was used as for odor threshold concentration measurement. A 22-d-old culture of Microcystis was pressurized, and after centrifugation the cells were resuspended in fresh medium (4.7 $\mathrm{nmol} \mathrm{chl} a / \mathrm{ml}$ ). A volume of $2 \mathrm{ml}$ of this suspension was centrifuged in an Eppendorf vial and added to $1 \mathrm{ml}$ of the same Scenedesmus suspension that was supplied continuously as food source in the toximeter. A volume of $0.35 \mathrm{ml}$ of this mixed cell suspension was injected with a 
syringe through the wall of the Tygon inflow tube directly before the peristaltic pump to avoid any pressure pulse in the cuvette. The time lag for the reaction was ca. $9 \mathrm{~min}$.

Liberation of $\beta$-Cyclocitral by Daphnia The liberation of $\beta$ cyclocitral by feeding Daphnia was measured by using a young culture of Microcystis (5-d-old). To reduce sedimentation of the cells to a minimum, the cell suspensions were not pressurized before centrifugation (Sorvall SLA-1500, $5 \mathrm{~min}$ at 5,000 rpm). The cell pellets were resuspended in half strength cyanobacterial medium to a volume of $500 \mathrm{ml}$ to achieve a cell abundance and chlorophyll $a$ concentration of $1.7 \times 10^{6}$ cells / $\mathrm{ml}$ and $188 \pm 13 \mathrm{pmol} / \mathrm{ml}$, respectively. For the first experiment (A), we used 155 individuals of a mixed age class of D. magna with all stages of development. For the second experiment (B), 325 individuals of a more uniform age class (3.5-wk-old) were used. Incubations were carried out in 1-1 glass bottles closed with a screw cap (to avoid loss of the liberated volatile $\beta$-cyclocitral) at $20^{\circ} \mathrm{C}$ and constant illumination of $2 \mu \mathrm{molm}^{-2} \mathrm{~s}^{-1}$ (near the light compensation level of Microcystis). Liberation of $\beta$ cyclocitral was measured over $20.5 \mathrm{hr}$ following the addition of D. magna. At different time intervals, the bottles were opened, allowing a short air exchange and retrieval of $5 \mathrm{ml}$ of Microcystis suspension, from which the cells were removed by filtration through a glass fiber filter under low vacuum. The filtrate was added to $45 \mathrm{ml}$ of water containing $2 \mu \mathrm{l}$ internal standard solution and $10 \mathrm{~g} \mathrm{NaCl}$. Volatiles were recovered and analyzed by using closed-loop stripping and GC-MS analysis, as described above.

Liberation of $\beta$-Cyclocitral in a Microcystis Culture To determine the liberation of $\beta$-cyclocitral in a culture of Microcystis, $20 \mathrm{ml}$ of a Microcystis suspension were centrifuged, and the cell pellet was resuspended in half strength cyanobacterial medium. The suspension was transferred into 1-1 glass bottles and incubated under the same conditions as in the Daphnia experiment (see above). After different time intervals, $10 \mathrm{ml}$ samples were removed, and the cells were separated by filtration through a glass fiber filter GF 6 . The filtrate containing the liberated $\beta$ cyclocitral was stripped and analyzed by GC-MS. Single ion monitoring $(\mathrm{m} / \mathrm{z} 152$ for measurement and $\mathrm{m} / \mathrm{z} 137$ for control) was used for detection of $\beta$-cyclocitral and pulegon that was added as an internal standard. The filter with the Microcystis cells was transferred into a stripping vial, covered with $10 \mathrm{ml}$ of $1 / 2$ strength medium and frozen at $-20^{\circ} \mathrm{C}$. On the next day, the suspension was melted, amended with $40 \mathrm{ml}$ of medium, and incubated for $1 \mathrm{hr}$ to complete the activation of the $\beta$-carotene oxigenase. After stripping, full spectra were obtained by GC-MS analysis from which the molecular ion $(\mathrm{m} / \mathrm{z}$ 152) was extracted to calculate the amount of $\beta$-cyclocitral.
Statistical Analysis We tested for effects of different concentrations of $\beta$-cyclocitral by pairwise comparison of the swimming velocity before and after the addition of the respective concentration of $\beta$-cyclocitral. As the same animals were used for the measurement of velocity before and after addition of $\beta$-cyclocitral, both values were regarded as dependent. Accordingly, $t$-tests for dependent samples were used to test for significant effects of a given concentration of $\beta$-cyclocitral. Data were tested for normality (Shapiro-Wilk $W$ test) and for homogeneity of variance (Levene's test). A level of significance of $P=$ 0.05 was applied. Analyses were performed using the software package Statistica 6.0.

\section{Results}

Microcystis NRC-1 produced a limited number of VOCs when activated by salt-induced cell rupture. The VOCs were dominated by $\beta$-cyclocitral and to a lesser extent by the long-chain hydrocarbons heptadecane, octadecane, 7-methylheptadecane (characteristic fragment ions at $\mathrm{m} / \mathrm{z}$ 168 and $\mathrm{m} / \mathrm{z}$ 112), and 6-methylheptadecane $(\mathrm{m} / z 182$ and $\mathrm{m} / \mathrm{z}$ 98). Isopropylthiol and its derivatives, known to be produced by other Microcystis strains (Jüttner 1984), were not detected. When Microcystis cells were killed by adding trifluoroacetic acid to minimize the activation of the carotene oxygenase by denaturation of the proteins, the per capita $\beta$-cyclocitral production was extremely low (2.6 amol / cell), indicating that minimal amounts of this VOC-less than $3.4 \%$ of the total production capacitywere present in intact cells.

When added to the toximeter inflow, a cell suspension containing Microcystis NRC-1 initiated an increase in $D$. magna swimming velocity from an average baseline level below 0.6 to $0.8 \mathrm{~cm} / \mathrm{sec}$ (Fig. 1). In contrast, the injection of a pure Scenedesmus suspension did not cause a similar increase of swimming velocity

To investigate whether $\beta$-cyclocitral production by Microcystis is responsible for this grazer response, the toximeter inflow of riverbank filtrate was replaced by riverbank filtrate spiked with this VOC. Again, we observed an increase in swimming velocity following this treatment. However, with continued addition of $\beta$-cyclocitral a rapid acclimation also was apparent (as similarly observed in our earlier work; Watson et al. 2007). With prolonged application of spiked water, Daphnia swimming velocity finally decreased to the initial value before treatment. Based on the above results, we evaluated the odor threshold concentration for this grazer by exposing the animals to a series of different $\beta$-cyclocitral concentrations (Fig. 2). Upon the addition of $2.5 \mu \mathrm{mol} / 1 \beta$ cyclocitral, the swimming velocity of Daphnia increased 
Fig. 1 Swimming velocity of Daphnia magna in the toximeter cell. Individual points represent mean values of measures from eight individuals, measured at $100 \mathrm{sec}$ intervals. Arrows indicate addition of $0.35 \mathrm{ml}$ of a Microcystis NRC-1 suspension to the inflowing water-Scenedesmus stream

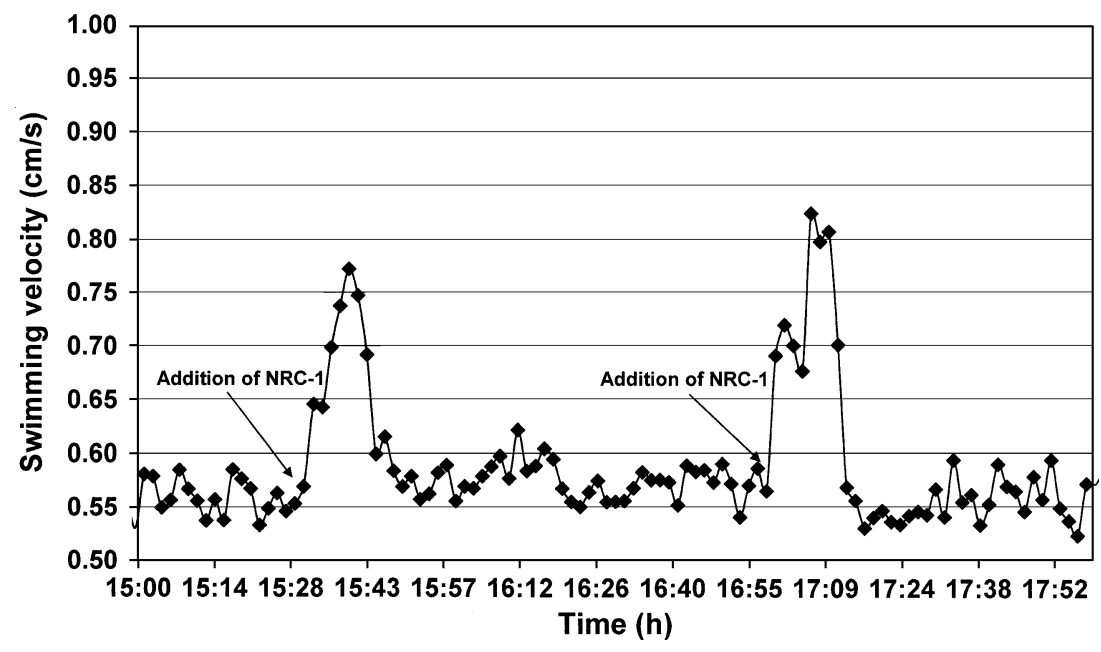

significantly from 0.48 to $0.65 \mathrm{~cm} / \mathrm{sec}$ (Fig. 2, Table 1). A similarly significant increase from 0.60 to $0.72 \mathrm{~cm} / \mathrm{sec}$ was observed upon addition of $750 \mathrm{nmol} / 1 \beta$-cyclocitral (Fig. 2, Table 1). However, $250 \mathrm{nmol} / 1$ of $\beta$-cyclocitral did not affect Daphnia's swimming velocity (Fig. 2, Table 1).

Experiments conducted to measure $\beta$-cyclocitral liberation from Microcystis by Daphnia grazing showed that initially, virtually no $\beta$-cyclocitral was detectable in the medium, but after a lag phase the concentration of this VOC increased continuously (Fig. 3). In experiment A, an older population of Daphnia magna was used that included individuals in all stages of development, while for experiment B, 3.5-wk-old mothers and their neonates were chosen. Following $20.5 \mathrm{hr}$ of feeding on the Microcystis suspensions, the crustaceans liberated 65 and 55 fmol $\beta$ cyclocitral / Daphnia / min in experiment A and B,

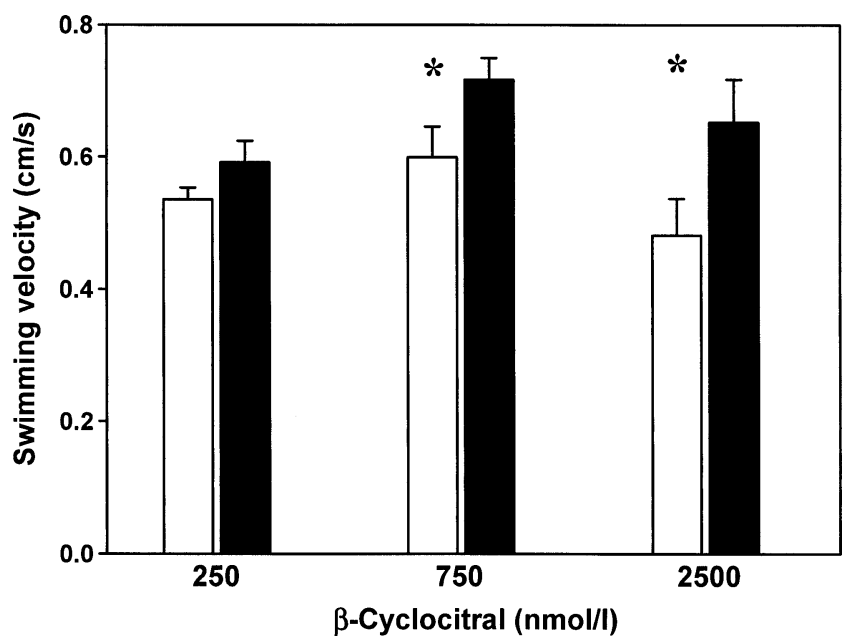

Fig. 2 Mean swimming velocity ( $+\mathrm{SE}, N=3)$ of Daphnia magna before (white columns) and after (black columns) addition of different concentrations of $\beta$-cyclocitral. Mean values are based on independent experiments performed at different days. Statistically significant differences in swimming velocity between pre- and post- $\beta$-cyclocitral addition are indicated by an asterisk respectively. This cor6responded to an activation of 14 and 12 Microcystis cells / Daphnia / s, respectively, assuming the same activation efficiency of the carotene oxygenase as observed by a freeze-thaw cycle. The liberation of $\beta$-cyclocitral in a Microcystis culture exposed to the same environmental conditions is shown (Fig. 4). The data demonstrate that most cell production of $\beta$ cyclocitral occurs with cell rupture and activation of carotene oxygenase, while the amount liberated by intact cells and dissolved in the medium is extremely small. The relative proportion of liberated $\beta$-cyclocitral to the total maximum cell production capacity of this compound was $0.04 \%$ at the beginning and $0.15 \%$ at the end of the $42 \mathrm{hr}$ incubation period.

To quantify the kinetics of $\beta$-cyclocitral production following cell damage, we applied two different techniques to activate the carotene oxygenase responsible for the formation of this VOC: a freeze-thaw cycle that used liquid nitrogen; and an application of a $20 \% \mathrm{NaCl}$ solution. Both treatments caused rapid $\beta$-cyclocitral formation, but the activation by an osmotic shock required an incubation period considerably longer than $80 \mathrm{~min}$ to achieve the maximum potential yield per cell (Fig. 5). A more efficient activation of carotene oxygenase was achieved by using a freeze-thaw process with liquid nitrogen. This procedure was more effective than the activation by $\mathrm{NaCl}$ addition. About $48 \%$ of the final concentration of $\beta$-cyclocitral

Table 1 Results of pair-wise comparisons of swimming velocities of Daphnia magna before and after the addition of known concentrations of $\beta$-cyclocitral ( $t$-test for dependent samples)

\begin{tabular}{llll}
\hline B-cyclocitral & $d f$ & $t$-value & $p$ \\
\hline $250 \mathrm{nM}$ & 2 & -2.6250 & 0.120 \\
$750 \mathrm{nM}$ & 2 & -4.4900 & $\mathbf{0 . 0 4 6}$ \\
$2.5 \mu \mathrm{M}$ & 2 & -11.798 & $\mathbf{0 . 0 0 7}$ \\
\hline
\end{tabular}

$P$-values given in bold indicate significant differences 


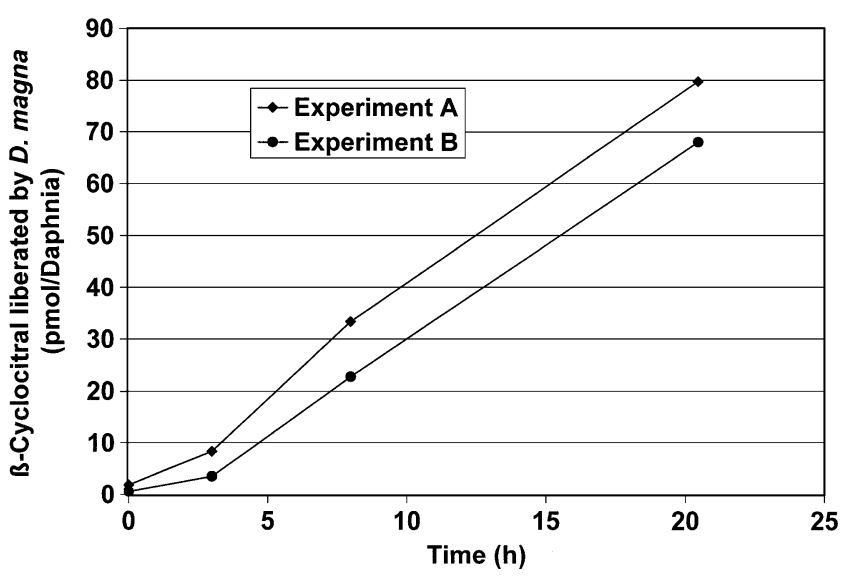

Fig. 3 Liberation of $\beta$-cyclocitral from Microcystis by Daphnia magna feeding (pmol / Daphnia). A-155 individuals of Daphnia at all developmental stages, B-3.5-wk-old mothers and neonates (325 individuals)

already was present by $\sim 5$ min (Fig. 6) using the freezethaw process. The completion of the oxygenase reaction occurred in less than 90 min with only a marginal further increase in $\beta$-cyclocitral formation in the total observation period of 1,440 min when the experiment was terminated. Although the first concentration measurements of $\beta$ cyclocitral in both Figs. 5 and 6 are labelled at 0 min, this in fact represents 5 min following the initial Microcystis cell activation by the osmotic shock or thawing process and subsequent centrifugation separation process.

Age-dependent changes in $\beta$-cyclocitral production capacity by Microcystis were investigated by using batch cultures of Microcystis NRC-1 grown over periods between 16 and 207 days after transfer into new growth medium. With the exception of the 16-d-old culture, the cells were at a stationary growth phase. Activation was initiated by a liquid nitrogen freeze-thaw cycle, and $\beta$-cyclocitral production was measured over a $90 \mathrm{~min}$ incubation period. The results showed no consistent age-dependant change of the $\beta$-cyclocitral production capacity between cultures, but a significant increase in cellular chlorophyll $a$ content with increasing age, translating to a lower $\beta$-cyclocitral production capacity per unit of chlorophyll $a$. (Table 2).

\section{Discussion}

The experiments provide new insight into grazercyanobacterial/algal interactions and show that chemical ecology may play a significant, taxon-specific role in facilitating grazer selectivity against bloom forming cyanobacteria. Our results showed a marked behavioral change in the common crustacean grazer Daphnia magna in response to the appearance of detectable levels of $\beta$-cyclocitral in the swimming medium. This implies that $\beta$-cyclocitral may provide a significant and exclusive competitive advantage to Microcystis among planktonic cyanobacterial/algal communities. However, while unique to this cyanobacterial genus, our related work indicates no apparent differentiation at the species level or relationship to toxicity. The specific $\beta$-carotene $7,8\left(7^{\prime}, 8^{\prime}\right)$ oxygenase involved in this process (Jüttner and Höflacher 1985) appears to be coded for by all Microcystis species, with $\beta$-cyclocitral production documented in all species tested to date (Jüttner 1984). These findings support our central hypothesis that $\beta$ cyclocitral acts as a genus-specific grazer repellent for these bloom forming cyanobacteria and facilitates optimal grazer foraging by acting as an effective signal of an unsuitable food source.
Fig. 4 Liberation of $\beta$-cyclocitral in a culture of Microcystis. Diamonds: formation capacity of the living cells; squares: dissolved fraction in the medium

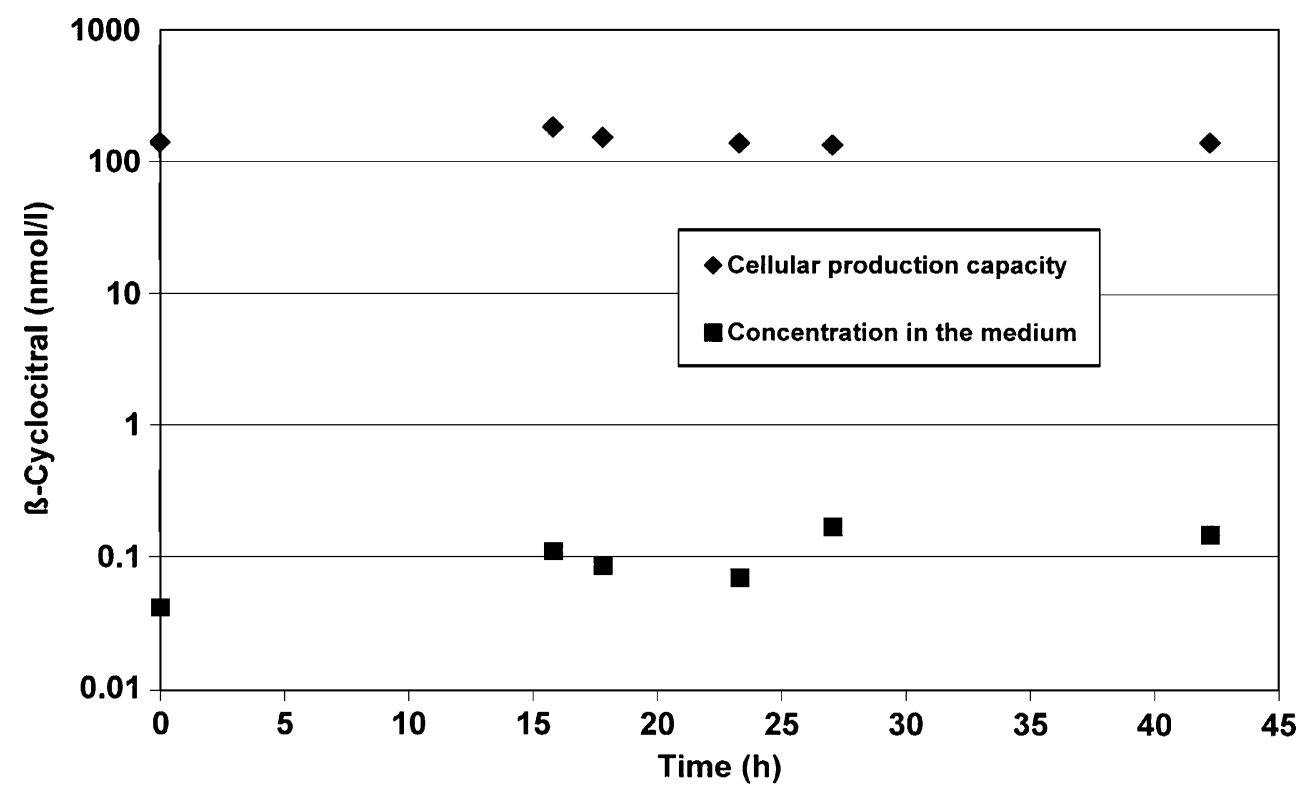




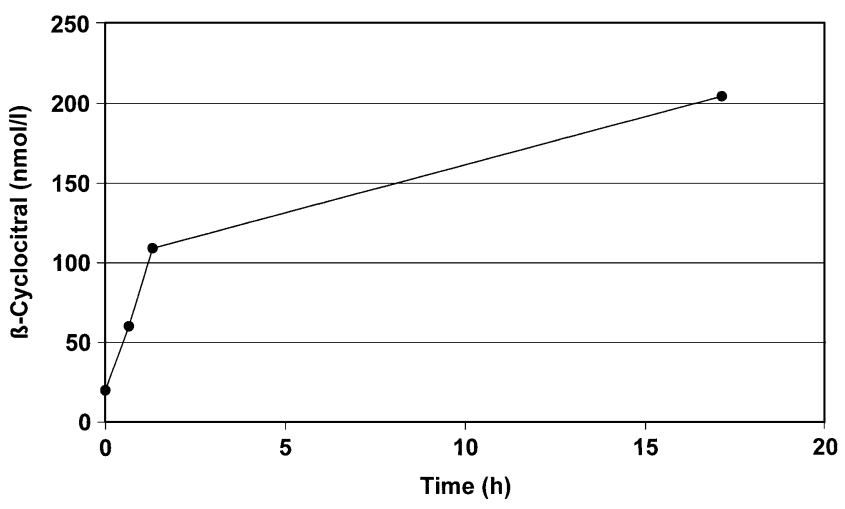

Fig. 5 Formation kinetics of $\beta$-cyclocitral (integration units / $\mathrm{ml}$ suspension) upon activation of Microcystis with an osmotic shock $(20 \% \mathrm{NaCl})$. The time-scale (X-axis) starts at the point of complete solution of the solid $\mathrm{NaCl}$ and separation of the cell matter from the aqueous phase by centrifugation

The tenet that some cyanobacteria are a poor food source and/or selectively avoided by crustaceans is as old as the study of Limnology (Birge 1898). The later development of quantitative measurements that used ${ }^{14} \mathrm{C}$-labelled food organisms, showed clearly that compared to algae from other taxonomic groups, Microcystis aeruginosa strongly inhibited crustacean ingestion rates (Sorokin 1968). This selective prey uptake was manifested as strong changes in the beat and movement rates of the thoracic appendages, mandibules, maxillules, etc. (Lampert 1982; Fulton and Paerl 1987b; Rohrlack et al. 1999a; Ghadouani et al. 2004). To date, however, studies have failed to implicate the primary toxins produced by many Microcystis (microcystin, MC) with this behavioral reaction, and no other chemicals have been linked with this grazer response. For example, MCproducing and non-producing Microcystis strains exhibit the same inhibitory reaction among grazers, and MCs have been ruled out as the causative agents in the avoidance reaction (Rohrlack et al. 1999b; Ghadouani et al. 2004). Similarly, this has been shown for isopropylsulfide producing and deficient Microcystis strains (Jungmann et al. 1991).

Unlike calanoid copepods, which are highly cued raptoral grazers, Daphnia are not considered to be selective feeders (Friedman and Strickler 1975; Poulet and Marsot 1978; DeMott 1986; Fulton and Paerl 1987b). Nevertheless, daphnids may have developed mechanisms to select particles based on morphological, physical (Hartmann and Kunkel 1991), and chemical cues (Jensen et al. 2001). Our experiments demonstrate clearly that Daphnia can detect the presence of trace levels of $\beta$-cyclocitral and respond to this with a behavioral change. We propose that a phobic reaction is initiated in these crustaceans when they encounter sufficient concentration differences of $\beta$ cyclocitral near damaged Microcystis cells, or when release of this VOC has occurred through grazing attack or by disruptive agents of some cells of the Microcystis colony.
We interpret this behavioral response as a phobic reaction, because previous toximeter assays also have shown an apparent decrease in the measured body size of Daphnia in response to $\beta$-cyclocitral, most likely reflecting changes from an upright, lateral to a dorsal or horizontal orientation, and/or in the trajectory of their motion as detected by the stationary tracking camera (Watson et al. 2007). It is important to note that the phobic reaction to $\beta$-cyclocitral ceased within a few minutes of exposure, even when high VOC concentrations persisted. This demonstrates that chemical gradients are essential to elicit a response, and that the animals rapidly acclimate to a given $\beta$-cyclocitral concentration, since after exposure they remain desensitized for over an hour to any subsequent application of this compound. This rapid acclimation to $\beta$-cyclocitral means that any effect on daphnid ingestion rate cannot be detected by using conventional feeding experiments with ${ }^{14} \mathrm{C}$ labelled Microcystis food, and may explain some of the ambiguities in previous studies of this grazer interaction. In addition, the acclimation reaction demonstrates clearly that the intensively studied permanent ingestion inhibition caused by Microcystis cells is the result of an unknown deterrent rather than $\beta$-cyclocitral. Previous reports agreed in showing a rapidly reversible inhibition of the deterrents as soon as suitable food was offered (Ghadouani et al. 2004).

We could only detect trace amounts of $\beta$-cyclocitral in intact Microcystis cells, and even these likely were the result of procedural artefacts caused by a small number of damaged cells. The formation of $\beta$-cyclocitral is achieved rapidly by activation of the $\beta$-carotene oxygenase pathway that cleaves $\beta$-carotene into crocetindial and two molecules of $\beta$-cyclocitral. Experimentally, this activation can be caused by any mechanism that disintegrates the physiological integrity of the cells, such as a freeze-thaw cycle,

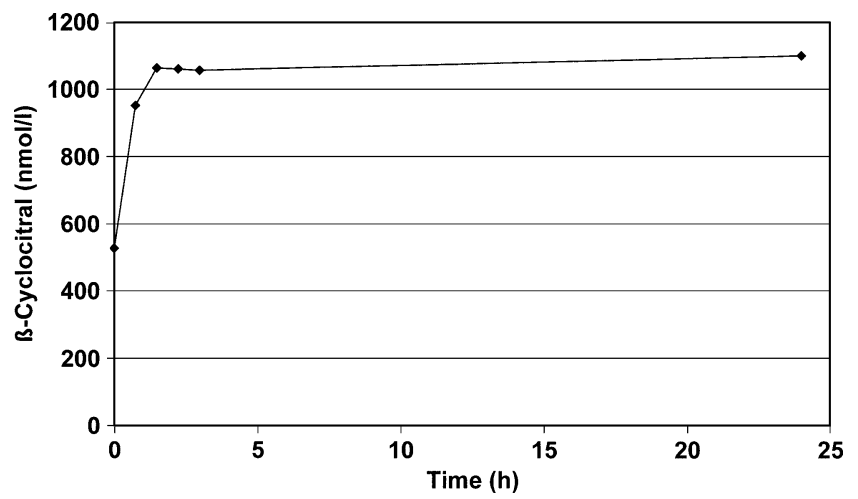

Fig. 6 Formation kinetics of $\beta$-cyclocitral upon activation of Microcystis (pmol $\beta$-cyclocitral $/ \mathrm{ml}$ suspension) by a freeze-thaw cycle and subsequent reaction time at ambient temperature $\left(23^{\circ} \mathrm{C}\right)$. The timescale (X-axis) starts at the point of complete melting of the cell suspension and separation of the cell matter from the aqueous phase by centrifugation 
Table 2 Age-dependant (days) capacity of Microcystis NRC-1 to form $\beta$-cyclocitral (amol ß-cyclocitral per cell, SD in brackets, $N=3$ ). The chlorophyll $a$ concentration per cell (amol chl $a$ per cell) and the ratio amol chlorophyll $a$ per amol

B-cyclocitral are also given

\begin{tabular}{lccc}
\hline Culture age (d) & amol B-cyclocitral/ cell & amol Chl $a$ / cell & amol chl $a$ / amol B-cyclocitral \\
\hline 16 & $77( \pm 5.5)$ & $127( \pm 4.3)$ & 1.6 \\
20 & $61( \pm 17)$ & $108( \pm 1.6)$ & 1.8 \\
52 & $49( \pm 7.6)$ & $109( \pm 1.7)$ & 2.2 \\
141 & $47( \pm 5.9)$ & $191( \pm 7.8)$ & 4.1 \\
207 & $65( \pm 2.2)$ & $201( \pm 2.5)$ & 3.1 \\
\hline
\end{tabular}

osmotic shock, mechanical damage, or addition of organic solvents. Under natural conditions, the formation of $\beta$ cyclocitral may be caused by Daphnia appendage bristles (Fryer 1991), which may puncture Microcystis cells and thus initiate $\beta$-carotene oxygenase activation. This activation may be continued and induced during ingestion and gut passage. Our feeding experiments with Daphnia and Microcystis NRC-1 under simulated natural conditions indicate that the activation of $\sim 12-14$ Microcystis cells per second per grazer is sufficient to elicit the behavioral response. In many lakes, a colonial matrix can contain up to several hundred Microcystis cells, and wounding one or several cells could produce a $\beta$-cyclocitral odor plume at sufficient concentrations to be detected by grazers. The adaptive function of this compound as a repellent would be afforded largely to Microcystis colonies, where a limited number of sacrificed cells can provide chemical protection to the majority. That is even more important because the growth rate of cells in colonies is comparable to that of single cells, and the energetic drawback of colonial growth is small (Nielsen 2006).

Our quantitative measurements estimate that the maximum theoretical intracellular $\beta$-cyclocitral concentration in an activated Microcystis cell (for a young cell, estimated to be $2.2 \mathrm{mM}$ ) would be some 3,000 times higher than the odor threshold concentration for Daphnia magna (750 nmol/l). Even where $\beta$-cyclocitral is rapidly diluted from the microzone around the activated cell(s), the concentration would be sufficient to initiate a phobic reaction by Daphnia, particularly where more than one cell is activated. This represents an effective chemical defense mechanism for Microcystis, since detection of the compound leads to a change in grazer orientation and an increase in swimming velocity, which we interpret as an avoidance reaction. In fact, olfactory receptors are widely distributed among invertebrate grazers including Daphnia, which may use the initial grazing-induced release of $\beta$ cyclocitral and other VOCs as a cue to reduce their ingestion of poor cyanobacterial and algal food.

The $\beta$-cyclocitral formation kinetics showed that the oxygenase reaction required some time to reach the maximum potential yield. Because the reaction mechanism is unclear, it is difficult to speculate which reaction step is rate-limiting. The ecological implication is that $\beta$ - cyclocitral production continues for some time following cell damage, thus allowing the formation of a transient odor plume or a microzone around a Microcystis colony (Blackburn et al. 1998) and thus reducing the probability of further grazer attack. Furthermore, it is feasible that sequestration of the liberated $\beta$-cyclocitral by the colonial mucilage could occur, which would effectively prolong the persistence of the VOC plume.

The defense reaction that initiates $\beta$-cyclocitral formation is constitutively present in Microcystis, and minimal differences in this capacity were observed as a function of age. Cells at late stationary phase (207 days) still exhibited this capacity, although an increase in their cell chlorophyll $a$ content translated to a decrease in $\beta$-cyclocitral production per chlorophyll $a$. Thus, under natural conditions, cells and colonies at all stages of growth maintain this grazer defense mechanism.

The formation of $\beta$-cyclocitral controls the residual amount of $\beta$-carotene in ingested Microcystis cells. Since two molecules of $\beta$-cyclocitral are formed from one molecule of $\beta$-carotene (Jüttner and Höflacher 1985), at least 30.5 amol $\beta$-carotene are required to produce 61 amol $\beta$-cyclocitral in a Microcystis cell. This is consistent with measured pigment content, assuming that most of the available $\beta$-carotene is oxidatively cleaved and that Microcystis NRC-1 has a chlorophyll $a$ to $\beta$-carotene molar ratio comparable to that of other Microcystis strains (e.g., 2.4 and 4.0 in SAG 1450-1 and PCC 7806, respectively; Stransky and Hager 1970; Jüttner and Höflacher 1985). It can be hypothesized further that the above-described grazer defense mechanism also may act to reduce the food value of the Microcystis cells themselves. Photoreceptors are known for Daphnia, and constituents of vitamin A (retinal and opsin) are likely key components of these receptors (Kashiyama et al. 2009). The grazing-activated cleavage of $\beta$-carotene by $7,8\left(7^{\prime}, 8^{\prime}\right)$ carotene oxygenase yields a product that cannot be used as a precursor for retinal. Once Microcystis cells are attacked, this catalytic process hypothetically might contribute to vitamin A deficiency by decreasing available levels of the precursor in a food supply. Depletion of $\beta$-carotene supply, however, could only be expected in those cases where Microcystis is the major food component of a Daphnia population. 
Effective defense strategies in predator-prey interactions often involve multi-tiered responses that are difficult to fully characterize. In this study, we demonstrated that the production of $\beta$-cyclocitral by Microcystis acts as a frontline chemical signal of an unsuitable food organism. It is triggered by grazer attack and is the first such infochemical identified in these cyanobacteria. From the grazer's perspective, this warning signal is justified by the presence of potent oligopeptides and other bioactive toxins in the cyanobacterial cells (Trubetskova and Haney 2006).To reinforce grazer recognition of Microcystis as an unsuitable food source, a logical next step in the signalling process would be through the production and intracellular storage of other chemical deterrents which, when present in the ingested food material, would act to reduce grazer ingestion rate. In fact, suppressed ingestion activity has been observed in a number of grazer feeding studies with Microcystis (e.g., Rohrlack et al. 1999a, b), but the chemical agent(s) have not been identified (although microcystins have been implicated by some authors, Kim et al. 2003). It is unlikely, however, that microcystins play a major role in grazer defense since microcystin-deplete colonies are frequently found in natural assemblages. On the other hand, digestive protease inhibitors are far more widely produced and found in almost every cyanobacterial bloom (Agrawal et al. 2005; Schwarzenberger et al. 2010), and it is possible that these compounds may act to suppress grazing. Future research in this area would contribute significant insight into the role of chemical ecology in top down regulation of noxious blooms.

Acknowledgements F.J. thanks J. Pernthaler, Limnological Station, University of Zürich, for continuous support.

\section{References}

Agrawal, M. K., Zitt, A., Bagchi, D., Weckesser, J., Bagchi, S. N., and VON ELERT E. 2005. Characterization of proteases in guts of Daphnia magna and their inhibition by Microcystis aeruginosa PCC 7806. Environ. Toxicol. 20:314-322

BenNDORF, J., and HenNing, M. 1989. Daphnia and toxic blooms of Microcystis aeruginosa in Bautzen Reservoir (GDR). Int. Rev. ges. Hydrobiol. 74:233-248.

BIRGE, E. A. 1898. Plankton studies on Lake Mendota. II: The crustacea of the plankton from July, 1894, to December, 1896. Trans. Wis. Acad. Sci. Arts Lett. 11:274-451.

Bister, B., Keller, S., Baumann, H. I., Nicholson, G., Weist, S., Jung, G., SÜssmuth, R. D., and JÜtTNER, F. 2004. Cyanopeptolin 963A - a chymotrypsin inhibitor of Microcystis PCC 7806. J. Nat. Prod. 67:1755-1757.

Blackburn, N., Fenchel, T., and Mitchell, J. 1998. Microscale nutrient patches in planktonic habitats shown by chemotactic bacteria. Science 282:2254-2256.

Boland, W., Pohnert, G., and MeIER, I. 1995. Pericyclic reactions in nature: spontaneous Cope rearrangement inactivates algae pheromones. Angew. Chem. Int. Ed. Engl. 34:1602-1604.
BuRns, C. W. 1968. The relationship between body size of filterfeeding cladocera and the maximum size of particle ingested. Limnol. Oceanogr. 13:675-678.

DemotT, W. R. 1986. The role of taste in food selection by freshwater zooplankton. Oecologia 69:334-340.

Demott, W. R., and Tessier, A. J. 2002. Stoichiometric constraints vs. algal defenses: testing mechanisms of zooplankton food limitation. Ecology 83:3426-3433.

Demott, W. R., Zhang, Q. X., and Carmichael, W. W. 1991. Effects of toxic cyanobacteria and purified toxins on the survival and feeding of a copepod and three species of Daphnia. Limnol. Oceanogr. 36:1346-1357.

Dokulit, M. T., and TeuBnER, K. 2000. Cyanobacterial dominance in lakes. Hydrobiologia 438:1-12.

DURRER, M., ZIMMERMANN, U., and JÜTTNER, F. 1999. Dissolved and particle-bound geosmin in a mesotrophic lake (Lake Zürich): Spatial and seasonal distribution and the effect of grazers. Water Res. 33:3628-3636.

FINK, P. 2007. Ecological functions of volatile organic compounds in aquatic systems. Mar. Freshw. Behav. Physiol. 40:155-168.

FrIEDMAN, M. M., and STRICKLER, J. R. 1975. Chemoreceptors and feeding in calanoid copepods (Arthropoda: Crustacea). Proc. Natl. Acad. Sci. USA 72:4185-4188.

FRYER, G. 1991. Functional morphology and the adaptive radiation of the Daphniidae (Branchiopode: Anomopoda). Phil. Trans. R. Soc. London B. 331:1-99.

Fulton, R. S. III, and PAeRL, H. W. 1987a. Effects of colonial morphology on zooplankton utilization of algal resources during blue-green algal (Microcystis aeruginosa) blooms. Limnol. Oceanogr. 32: 634-644.

Fulton, R. S. III, and PAERL, H. W. 1987b. Toxic and inhibitory effects of the blue-green alga Microcystis aeruginosa on herbivorous zooplankton. J. Plankton Res. 9:837-855.

Ghadouani, A., Pinel-Alloul, B., Plath, K., CodD, G. A., and LAMPERT, W. 2004. Effects of Microcystis aeruginosa and purified microcystin-LR on the feeding behavior of Daphnia pulicaria. Limnol. Oceanogr. 49:666-679.

Han J, McCarthy, E. D., Calvin, M., and BenN, M. H. (1968) Hydrocarbon constituents of the blue-green algae Nostoc muscorum, Anacystis nidulans, Phormidium luridum and Chlorogloea fritschii. J. Chem. Soc., C, 2785-2791.

Hansson, L. A., Gustafsson, S., Rengefors, K., and Bomark, L. 2007. Cyanobacterial chemical warfare affects zooplankton community composition. Freshw. Biol. 52:1290-1301.

HartmanN, H. J., and Kunkel, D. D. 1991. Mechanisms of food selection in Daphnia. Hydrobiologia 225:129-154.

Hyenstrand, P., Blomqvist, P., and Petterson, A. 1998. Factors determining cyanobacterial success in aquatic systems: a literature review. Ergeb. Limnol. 51:41-62.

Ishida, K., OKita, Y., Matsuda, H., OKino, T., and Murakami, M. 1999. Aeruginosins, protease inhibitors from the cyanobacterium Microcystis aeruginosa. Tetrahedron 55:1097110988.

JARVIS, A. C., HART, R. C., and COMBrinK, S. 1987. Zooplankton feeding on size fractionated Microcystis colonies and Chlorella in a hypertrophic lake (Hartbeespoort Dam, South Africa): implications to resource utilization and zooplankton succession. $J$. Plankton Res. 9:1231-1249.

Jensen, K. H., Larsson, P., and Högstedt, G. 2001. Detecting food search in Daphnia in the field. Limnol. Oceanogr. 46:1013-1020.

Joosten, A. M. T. 2006. Flora of the Blue-Green Algae of the Netherlands. KNNV Publishing, Utrecht.

Jungmann, D., Henning, M., and JÜtTnER, F. 1991. Are the same compounds in Microcystis responsible for toxicity to Daphnia and inhibition of its filtering rate? Int. Rev. ges. Hydrobiol. $76: 47-56$. 
JÜTTNER, F. 1984. Characterization of Microcystis strains by alkyl sulfides and $\beta$-cyclocitral. Z. Naturforsch. 39c:867-871.

JÜTTNER, F. 1999. Allelochemical control of natural photoautotrophic biofilms, pp. 43-50, in C. W. Keevil, A. Godfree, D. Holt, and C. Dow (eds.). Biofilms in the Aquatic Environment. Royal Society of Chemistry, Special Vol. 242, Cambridge, UK.

JÜTTNER, F. 2005. Evidence that polyunsaturated aldehydes of diatoms are repellents for pelagic crustacean grazers. Aquat. Ecol. 39: 271-282.

JÜTTNER, F., and HÖFLACHER, B. 1985. Evidence of $\beta$-carotene 7,8 $\left(7^{\prime}, 8^{\prime}\right)$ oxygenase $(\beta$-cyclocitral, crocetindial generating) in Microcystis. Arch. Microbiol. 141:337-343.

JÜTTNER, F., and LÜTHI, H. 2008. Topology and enhanced toxicity of bound microcystins in Microcystis PCC 7806. Toxicon 51:388397.

Kashiyama, K., Seki, T., Numata, H., and Goto, S. G. 2009. Molecular characterization of visual pigments in Branchiopoda and the evolution of opsins in Arthropoda. Mol. Biol. Evol. 26:299-311.

KIM, J. H., YoOn, B. D., and OH, H. M. 2003. Rapid bioassay for microcystin toxicity based on feeding activity of Daphnia. Bull. Environ. Contam. Toxicol. 70:861-867.

Koski, M., Breteler, W. K., Schogt, N., Gonzales, S. and JAKOBSEN, H. H. 2006. Life-stage-specific differences in exploitation of food mixtures: diet mixing enhances copepod egg production but not juvenile development. J. Plankton Res. 28:919-936.

Kotak, B. G., Lam, A. K. Y., Prepas, E. E., Kenefick, S. L., and HRUDEY, S. E. 1995. Variability of the hepatotoxin microcystin-LR in hypereutrophic drinking-water lakes. J. Phycol. 31:248-263.

KrogmanN, D. W., Butalla, R., and SprinkLe, J. 1986. Blooms of cyanobacteria on the Potomac River. Plant Physiol. 80:667-671.

LAMPERT, W. 1982. Further studies on the inhibitory effect of the toxic blue-green Microcystis aeruginosa on the filtering rate of zooplankton. Arch. Hydrobiol. 95:207-220.

Lechelt, M., Blohm, W., Kirschneit, B., Pfeiffer, M., Gresens, E., Liley, J., Holz, R., LÜRing. C., and MoldaenKe, C. 2000. Monitoring of surface water by ultrasensitive Daphnia toximeter. Environ. Toxicol. 15:390-400.

NiELSEN, S. L. 2006. Size-dependent growth rates in eukaryotic and prokaryotic algae exemplified by green algae and cyanobacteria: comparisons between unicells and colonial growth forms. $J$. Plankton Res. 28:489-498.

OGAWA, T., and VERNON, L. P. 1971. Increased content of cytochromes 554 and 562 in Anabaena variabilis cells grown in presence of diphenylamine. Biochim. Biophys. Acta 226:88-97.

PortMANn, C., Blom, J. F., KAISER, M., BrUn, R., JÜtTNER, F., and GADEMANN, K. 2008. Isolation of aerucyclamides $\mathrm{C}$ and D and structure revision of microcyclamide 7806A: Heterocyclic ribosomal peptides from Microcystis aeruginosa PCC 7806 and their antiparasite evaluation. J. Nat. Prod. 71:1891-1896.

POULET, S. A., and MARSOT, P. 1978. Chemosensory grazing by marine calanoid copepods (Arthropoda: Crustacea). Science 200:1403-1405.

REYNOLDS, C. 2006. The Ecology of Phytoplankton. Cambridge University Press, Cambridge.

Rinta-Kanto, J. M., Konopko, E., Debruyn, J., Bourbonniere, R., BOYER, G. L., and WILHELM, S. 2009. Lake Erie Microcystis: Relationship between microcystin production, dynamics of genotypes and environmental parameters in a large lake. Harmful Algae 8:665-673.

RohrlaCK, T., HenNing, M., and KoHL, J. G. 1999a. Mechanisms of the inhibitory effect of the cyanobacterium Microcystis aeruginosa on Daphnia galeata's ingestion rate. J. Plankton Res. 21:1489-1500.

Rohrlack, T., DitTmann, E., Henning, M., BÖrner, T., and KOHL, J. G. 1999b. Role of microcystins in poisoning and food ingestion inhibition of Daphnia galeata caused by the cyanobacterium Microcystis aeruginosa. Appl. Environ. Microbiol. 65:737-739.

Rohrlack, T., Christoffersen, K., Hansen, P. E., Zhang, W., Czarnecki, O., Henning, M., Fastner, J., Erhard, M. NeILAN, B. A., and KAEBERNICK, M. 2003. Isolation, characterization, and quantitative analysis of microviridin $\mathrm{J}$, a new Microcystis metabolite toxic to Daphnia. J. Chem. Ecol. 29:1757-1770.

Schwarzenberger, A., Zitt, A., Kroth, P., Müller, S., and vON ELERT, E. 2010. Gene expression and activity of digestive proteases in Daphnia: effects of cyanobacterial protease inhibitors. BMC Biology 10:6.

SorokIN, J. I. 1968. The use of ${ }^{14} \mathrm{C}$ in the study of nutrition of aquatic animals. Int. Ver. Theoret. Angew. Limnol. Mitteilungen 16:1-41.

Stransky, H., and Hager, A. 1970. Das Carotinoidmuster und die Verbreitung des lichtinduzierten Xanthophyllcyclus in verschiedenen Algenklassen. IV. Cyanophyceae und Rhodophyceae. Arch. Mikrobiol. 72:84-96.

Trubetskova, I. L., and Haney, J. F. 2006. Effects of differing concentrations of microcystin-producing Microcystis aeruginosa on growth, reproduction, survivorship and offspring of Daphnia magna. Arch. Hydrobiol. 167:533-546.

von Elert, E., Martin-Creuzberg, D., and Le CoZ, J. R. 2003. Absence of sterols constrains carbon transfer between cyanobacteria and a freshwater herbivore (Daphnia galeata). Proc. R. Soc. Lond., Ser. B: Biol. Sci. 270:1209-1214.

von Elert, E., Agrawal, M. K., Gebauer, C., Jaensch, H., BAUER, U., and ZitT, A. 2004. Protease activity in gut Daphnia magna: evidence for trypsin and chymotrypsin enzymes. Comp. Biochem. Physiol. B, Biochem. Mol. Biol. 137:287-296.

WATSON, S. B. 2003. Cyanobacterial and eukaryotic algal odour compounds: signals or by-products? A review of their biological activity. Phycologia 42:332-350.

Watson, S. B., McCauley, E., and Downing, J. A. 1997. Patterns in phytoplankton taxonomic composition across temperate lakes of differing nutrient status. Limnol. Oceanogr.42:487-495.

Watson, S. B., JÜtTner, F., and Köster, O. 2007. Daphnia behavioural responses to taste and odour compounds: ecological significance and application as an inline treatment plant monitoring tool. Water Sci. Technol. 55:23-31.

WATSON, S. B., RiDAL. J., and BOYER, G. L. 2008. Taste and odour and cyanobacterial toxins: impairment, prediction, and management in the Great Lakes. Can. J. Fish. Aquat. Sci. 65:1779-1796.

WelKer, M., MARŠÁLEK, B., ŠEJNOHOVÁ, L., and VON DÖHREN, H. 2006. Detection and identification of oligopeptides in Microcystis (cyanobacteria) colonies: toward an understanding of metabolic diversity. Peptides 27:2090-2103.

Wilson, A. E., Sarnelle, O., and Tillmans, A. R. 2006. Effects of cyanobacterial toxicity and morphology on the population growth of freshwater zooplankton: meta-analyses of laboratory experiments. Limnol. Oceanogr. 51:1915-1924. 